\title{
Aplikasi Sistem Penerbitan Sertifikat PT. Sucofindo
}

\author{
Novianti Soleman, Rizal Sengkey, Agustinus Jacobus \\ Teknik Informatika Universitas Sam Ratulangi Manado, Indonesia. \\ novianti@gmail.com, sengkey@unsrat.ac.id, a.jacobus@unsrat.ac.id
}

\begin{abstract}
Abstrak - PT. Sucofindo adalah perusahaan inspeksi pertama di Indonesia yang bergerak dibidang jasa, PT. Sucofindo kini memiliki 5 jasa diantaranya pengujian dan analisis, sertifikasi, konsultasi, jasa pelatihan dan yang terakhir adalah jasa inspeksi atau audit. Dengan tingkat persaingan yang semakin tinggi dalam dunia bisnis tentunya sebuah usaha harus lebih meningkatkan upaya dan strategi agar dapat memberikan inovasi-inovasi baru bagi pelanggan. Sistem Penerbitan Sertifikat ini surveyor lebih mudah dalam mengerjakan tugas dan pekerjaan dilapangan, karena tidak perlu lagi ke kantor untuk membuat surat tugas dan surat instruksi kerja kepada admin operasional.
\end{abstract}

\section{Kata Kunci: PT. Sucofindo, Sistem Penerbitan, Sertifikat.}

Abstract- PT. Sucofindo is the first inspection company in Indonesia engaged in services. PT. Sucofindo now has 5 services including testing and analysis, certification, consulting, training services and the last is inspection or audit services. With the increasingly high level of competition in the business world, a business must increase efforts and strategies to provide new innovations for customers. This Certificate Issuance System is easier for surveyors to do tasks and jobs in the field, because there is no need to go to the office to make assignment letters and work instruction letters to the operational admin.

Keywords: PT. Sucofindo, Publishing System, Certificate.

\section{PENDAHULUAN}

Tingkat persaingan usaha kian ketat dan beragam dewasa ini. Kondisi ini melahirkan persaingan yang semakin tinggi dalam dunia bisnis, menyebabkan dunia usaha menjadi sangat kompetitif, iklim bisnis yang selalu berubah dan tidak pasti. Hal tersebut menuntut upaya dan strategi perusahaan yang tepat agar kelangsungan hidup perusahaan tetap terjamin.

Untuk mencapai visi dan misi, perusahaan membentuk strategi yang kemudian dijabarkan menjadi program kerja dan harus dieksekusi sehingga menghasilkan kinerja atau performa. Namun, banyak organisasi yang terjebak hanya berfokus pada strategi saja, kurang memperhatikan kepada eksekusi, padahal eksekusi sangat tergantung kepada aspek manusia. Sangat penting untuk membangun karakter individu di organisasi agar memiliki perilaku yang positif, sejalan dengan nilai-nilai organisasi serta yakin dengan visi-misi perusahaan.
Kemajuan teknologi informasi dan komunikasi yang mampu mnghadirkan kemudahan dan kecepatan akses informasi. Sebagian besar perusahaan dituntut harus melakukan efisiensi terhadap waktu dengan berbagai cara antara lain menawarkan suatu sistem untuk dapat mempercepat pekerjaan yang ada di perusahaan, seperti halnya yang ada di PT. Sucofindo Manado.

Sistem yang sedang berajalan di PT. Sucofindo cabang Manado ini sebagian besar sudah memakai sistem aplikasi, namun ada beberapa yang masih memakai sistem manual yaitu untuk pembuatan Surat Instruksi Kerja. Proses pembuatan Surat Instruksi Kerja ini membutuhkan waktu yang cukup lama sehingga petugas lapangan atau surveyor sering kali terlambat dalam melakukan pekerjaan. Untuk itu saya mengambil masalah ini sebagai penelitian Tugas Akhir saya.

Oleh sebab itu, penulis menyimpulkan untuk membuat suatu sistem atau aplikasi dimana aplikasi tersebut dapat membantu mempercepat proses penerbitan surat instruksi kerja dan tidak lagi menghambat pekerjaan petugas lapangan atau surveyor. Aplikasi yang akan dibuat yaitu sistem penerbitan sertifikat.

\section{A. PT. Sucofindo}

Perusahaan yang merupakan perusahaan inspeksi pertama di Indonesia, yaitu PT. Sucofindo yang didirikan pada 22 Oktober 1956 yang berperan dalam memberikan jasa pemastian bagi pelaku usaha untuk menjalankan proses bisnis dan transaksi usaha. Kantor pelayanan terdiri atas 29 cabang dan 34 unit layanan tersebar diseluruh pelosok Indonesia, dan 1 SBU Laboratorium yan berlokasi di Cibitung dan Laboratorium yang berlokasi di Surabaya. Tidak kurang dari 10.000 pelanggan bangga menggunakan sertifikasi hasil uji dan laporan survei dari Sucofindo dan lebih dari 2.000 pelanggan menggunakan logo (sertifikasi dan jaminan mutu) dari Sucofindo sebagai pencitraan merek bagi pelanggan. ${ }^{[1]}$

Sistem yang ada di PT. Sucofindo bisa dibilang ada beberapa bagian yang masih menggunakan sistem manual dan butuh waktu untuk penerbitannya, untuk itu dibutuhkan sebuah sistem informasi yang cepat dan akurat pada pembuatan / penerbitan dokumen untuk kedepannya ${ }^{[1]}$

\section{B. Sistem Penerbitan Sertifikat}

PT. Sucofindo melaksanakan pekerjaan sesuai dengan prosedur operasi baku yang mengacu pada standar internasional, serta prosedur lain yang diterima oleh dunia 
usaha pada sektor pertambangan batubara. Peralatan yang digunakan meliputi alat preparasi modern dan terkalibrasi serta dilengkapi dengan peralatan uji Informasi Strategis. Informasi ini digunakan untuk mengambil keputusan jangka panjang, yang mencakup informasi eksternal, rencana perluasan perusahaan, dan sebagainya.

\section{1) Standar}

Dalam melaksanakan pekerjaannya PT. Sucofindo merujuk pada standar / metode baku yang di akui baik nasional maupun internasional seperti: SNI (Standar Nasional Indonesia), ASTM (American Society for Testing and Material), BS (British Standard), ISO (International Organization for Standardization) JIS (Japanese Industrial Standarts), dan AS (Australian Standard).

2) Pelaksanaan

Pelaksanaan pengujian produk batubara dapat dilakukan melalui dua cara pendekatan:

a. Menggunakan sarana dan prasarana dan SDM yang disiapkan dan dikelola secara langsung oleh PT. Sucofindo.

b. Menggunakan sarana dan prasarana yang dimiliki pelanggan dan dioperasikan oleh PT. Sucofindo.

3) Pelaporan

Hasil analisis dari masing-masing peralatan laboratorium (data) dirangkum dalam sistem manajemen dan pelaporannya dituangkan dalam bentuk sertifikat maupun laporan. ${ }^{[1]}$

\section{Analisa dan Perancangan}

Analisis sistem didefinisikan bagaimana memahami dan menspesifikasi dengan detail apa yang harus dilakukan oleh sistem. Sementara system desain diartikan sebagai menjelaskan dengan detail bagaimana bagian-bagian dari sitem informasi dimplementasikan. Sedangkan perancangan sistem adalah rencana mengimplementasikan hasil dari analisis sistem yang dilaksanakan meliputi seluruh karakteristik sistem desain seperti spesifikasi file, ptosedur-prosedur operasi sesuai dengan kebutuhan pemakai. ${ }^{[3]}$

Pengertian analisis sistem adalah penguraian dari suatu sistem informasi yang utuh kedalam bagian-bagian komponennya dengn maksud untuk mengidentifikasikan dan mengevaluasi permasalahan, kesempatan, hambatan yang terjadi dan kebutuhan yang diharapkan sehingga dapat diusulkan perbaikan. ${ }^{[2]}$

Dalam proses penelitian analisa merupakan tahap akhir sebelum penarikan kesimpulan dilakukan. Pada awal tahapan, dilakukan proses pencarian serta pembatasan masalah. Selanjutnya, dilakukanlah proses penarikan hipotesa awal. Hipotesa awal ini berfungsi sebagai praduga awal sebelum proses penelitian dilakukan. ${ }^{[3]}$

\section{Sistem}

Sistem adalah kumpulan / group / komponen apapun yang saling berhubungan satu sama lain dan bekerja sama secara harmonis untuk mencapai satu tujuan tertentu. Terdapat dua kelompok pendekatan di dalam mendefinisikan sistem, yaitu yang menekankan pada prosedurnya dan yang menekankan pada elemen atau komponennya. ${ }^{[2]}$
Pendekatan sitem yang lebih menekankan pada prosedur mendefinisikan sistem sebagai "suatu jaringan kerja dari procedure-procedure yang saling berhubungan, berkumpul besama-sama untuk melakukan suatu kegiatan atau untuk menyelesaikan suatu sasaran yang tertentu" sedangkan pendekatan sistem yang lebih menekankan pada element atau komponennya mendefinisikan sebagai "kumpulan dari elemenelemen yang berinteraksi untuk mencapai suatu tujuan tertentu". [3]

Sistem merupakan elemen-elemen yang saling berkait dan bekerja sama untuk memroses masukan (input) yang ditujukan kepada sistem tersebut dan mengolah masukan tersebut sampai menghasilkan keluaran (output) yang diinginkan.

Sedangkan sistem secara sederhana dapat didefinisikan sebagai sekelompok elemen yang saling berhubungan atau berinteraksi hingga membentuk satu persatuan. ${ }^{[4]}$

\section{E. Sistem Basis Data}

Basis Data atau database adalah suatu kumpulan data terhubung (interrelated data) yang disimpan secara bersamasama pada suatu media, tanpa mengatap satu sama lain atau tidak perlu suatu kerangkapan data (controlled redudancy) dengan cara tertentu sehingga mudah digunakan atau ditampilkang kembali. [3]

Sistem basis data adalah sekumpulan database yang dapat dipakai secara bersama-sama, personal-personal yang merancang dan mengelola database, teknik-teknik untuk merancang dan mengelola database, serta komputer yang mendukungnya. Sistem basis data adalah sistem terkomputerisasi yang tujuan utamanya adalah memelihara data yang sudah diolah atau informasi dan membuat informasi tersedia saat dibutuhkan. Sistem basis data memiliki beberapa komponen pokok, yaitu:

1) Data

Data didalam sebuah basis data dapat disimpan secara terintegrasi (integrated) dan data dapat dipakai secara bersama-sama (shared).

2) Hardware (perangkat keras)

Terdiri dari semua perangkat komputer yang digunakan untuk pengelolaan sistem basis data, berupa (1) Peralatan untuk penyimpanan basis data, yaitu secondary storage, (2) Peralatan input dan output, (3) Peralatan komunikasi data, dan lain-lain.

3) Software (perangkat lunak)

Berfungsi sebagai perantara (interface) antara pemakai dengan data fisik pada basis data. Software pada basis data berupa DBMS atau program-program aplikasi dan prosedur-prosedur.

4) User atau pemakai

a. Database Administrator (DBA), orang atau tim yang bertugas mengelola sistem basis data secara keseluruhan.

b. Programmer, orang atau tim yang bertugas membuat program aplikasi.

c. End User, orang yang mengakses basis data melalui terminal dengan query language atau program aplikasi yang dibuat programmer. ${ }^{[4]}$ 


\section{METODOLOGI PENELITIAN}

\section{A. Objek dan Lokasi Penelitian}

Dalam pembuatan Sistem Penerbitan Sertifikat ini penulis penulis melakukan penelitian di PT. SUCOFINDO UP Manado tepatnya di Jl. Arie Lasut No. 31 Manado - 95231, Indonesia.

\section{B. Langkah-Langkah Penelitian \\ 1) Definisi Kebutuhan}

Identifikasi masalah dan definisi kebutuhan adalah tahap awal dalam melakukan penelitian, dari latar belakang dan rumusan masalah yang diangkat, dilakukan identifikasi mengenai masalah utama yang ada dalam penelitian ini. Identifikasi masalah dapat dilihat pada tabel I. statement matrix 2) Mendeain Model Sistem

Dalam tahap desain model sistem bertujuan untuk melakukan Perancangan sistem melalui hasil analisis yang telah dilakukan sebelumnya. Pada tahap ini peneliti melakukan beberapa hal sebagai berikut :

a. Merancang interface sistem

b. Merancang fitur dalam sistem

3) Implementasi

Dalam tahap implementasi bertujuan untuk membangun sistem berdasarkan hasil dari mendesain sistem yang telah di dapatkan. Berdasarkan hasil desain, dilakukan pembangunan (kontruksi) sistem berupa coding atau kodefikasi program. Kodefikasi merupakan proses penulisan source code atau kodekode sumber yang akan membangun sistem dari segi interface sistem dan logika atau proses dari sistem itu sendiri.

4) Dokumentasi

Dokumentasi adalah sebuah cara yang dilakukan untuk menyediakan dokumen. Dalam tahap ini dokumentasi yang dimaksud adalah dalam bentuk skripsi.

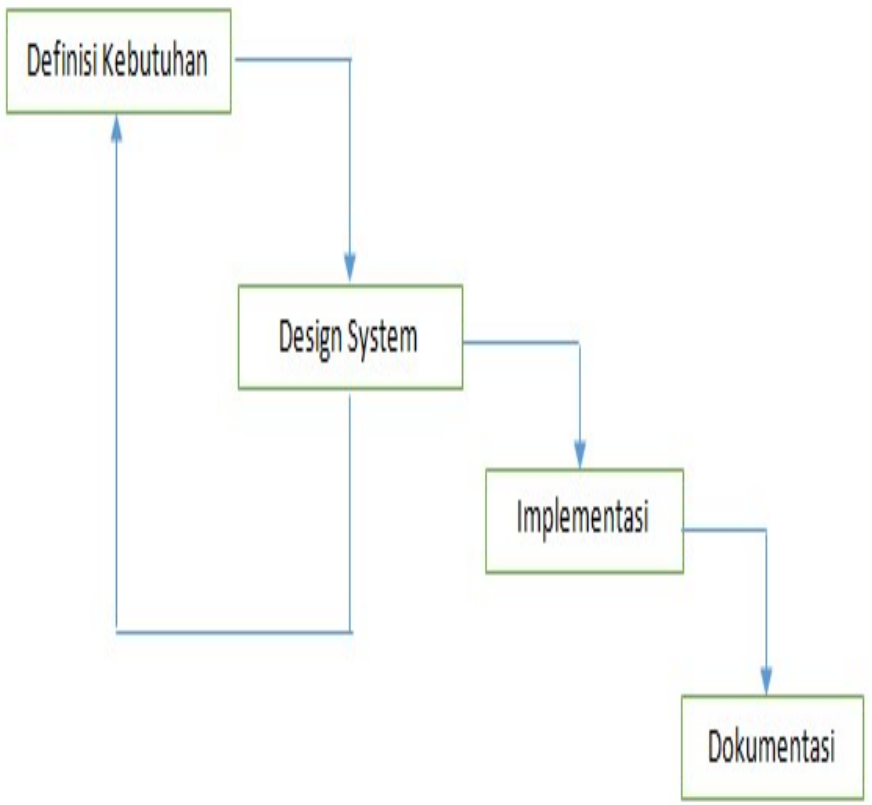

Gambar 1. Langkah-Langkah Penelitian

\section{Metode Pengumpulan Data}

Pada tahap pengumpulan data ini dilakukan dengan cara observasi langsung ke kantor PT. Sucofindo, wawancara, membagikan kuisoiner 20 sample untuk seluruh pegawai yang bekerja di PT. Sucofindo guna untuk mengetahui masalah yang ada dikantor tersebut. Adapun pengambilan data melalui studi pustaka yang data-datanya terbagi atas data primer dan data sekunder.

\section{1) Data Primer}

Data primer adalah data yang diperoleh langsung dari sumbernya saat melakukan observasi kepada petugas lapangan / surveyor yang ada di kantor PT. Sucofindo. Data tersebut berupa wawancara langsung yang selanjutnya dicatat oleh peneliti, untuk dijadikan bahan penelitian dalam membangun aplikasi sistem penerbitan sertifikat di PT. Sucofindo.

2) Data Sekunder

Pencarian data sekunder ini dilakukan diluar kantor, berupa artikel-artikel, buku-buku penunjang dan data-data hasil penelitian yang dapat menunjang perlengkapan dari penelitian dan dirangkum menjadi sebuah kontribusi penelitian seperti tulisan dibawah ini:

Metode penelitian mempunyai peran yang penting dalam suatu penelitian, dalam penelitian ini penulis mengambil metode penelitian sebagai berikut:

a. Studi Literatur

Pengumpulan refrensi dari berbagai sumber berupa data dan informasi yang bisa dijadikan acuan pembahasan yang berkaitan dengan penelitian yang penulis ambil. Tujuannya untuk mendukung teori-teori yang berkaitan dengan pembuatan sistem penerbitan sertifikat.

b. Wawancara

Metode pengumpulan data dengan melakukan wawancara ini adalah untuk mengetahui masalah-masalah yang ada di PT. SUCOFINDO UP Manado.

c. Observasi

Dilakukan dengan cara mengamati langsung prosedur yang berlaku di PT. SUCOFINDO Manado sehingga diperoleh gambaran untuk pembuatan Sistem Penerbitan Sertifikat.

TABEL I. STATEMENT MATRIX

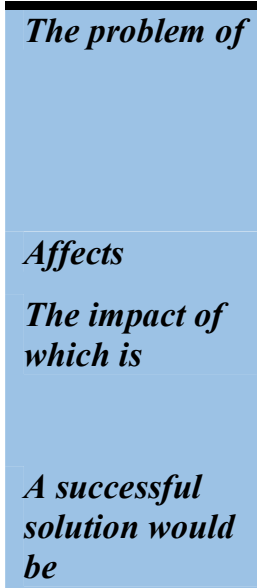

Proses penerbitan dokumen surat instruksi kerja masih menggunakan cara manual.

Butuh waktu lama untuk membuat surat instruksi kerja.

Waktu dan pekerjaan di lapangan

Menunda proses pekerjaan dilapangan.

Menunda waktu yang telah ditentukan dan disepakati oleh kedua pihak.

Merancang sebuah Sistem Penerbitan Sertifikat di PT. Sucofindo Manado dengan memasukan data-data yang diperlukan dalam penerbitan surat instruksi kerja, diantaranya adalah surat kofirmasi order dan surat tugas. 


\section{A. Business Process}

Gambar 2. Proses Bisnis (sebelum) adalah sebuah proses bisnis dari PT. Sucofindo sebelum dibuatkan sistem penerbitan sertifikat, dimana client mengajukan permintaan order dan dibuatkan oleh admin sebuah order confirmation lalu di setujui dan ditanda tangani oleh kepala unit pelayanan setelah itu dikembalikan lagi ke admin operasional untuk dibuatkan surat tugas dan surat instruksi kerja dan diteruskan ke bagian dukbis / umum untuk pengambilan alat dan bahan yang dibutuhkan oleh surveyor. Setelah surveyor menyelesaikan tugasnya dan membawa Hasil Pemeriksaan Lapangan (HPL), admin operasional membuatkan draft sertifikat lalu tandatangani dan di cap oleh kepala unit pelayanan diteruskan ke bagian keuangan untuk dibuatkan invoice dan terakhir diserahkan kepada client sertifikat dan invoice.

Gambar 3. Proses Bisnis (sesudah) adalah proses bisnis setelah dibuatnya sistem penerbitan sertifikat PT. Sucofindo. Seperti yang kita lihat bahwa surveyor tidak perlu lagi ke kantor untuk mengambil surat tugas dan surat instruksi kerja untuk disetujui oleh kepala unit pelayanan.

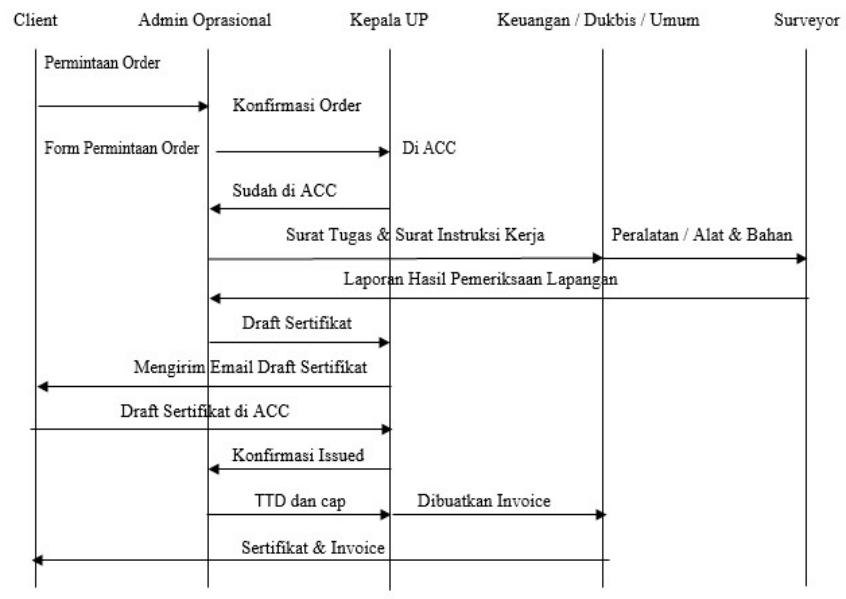

Gambar 2. Proses Bisnis (sebelum)

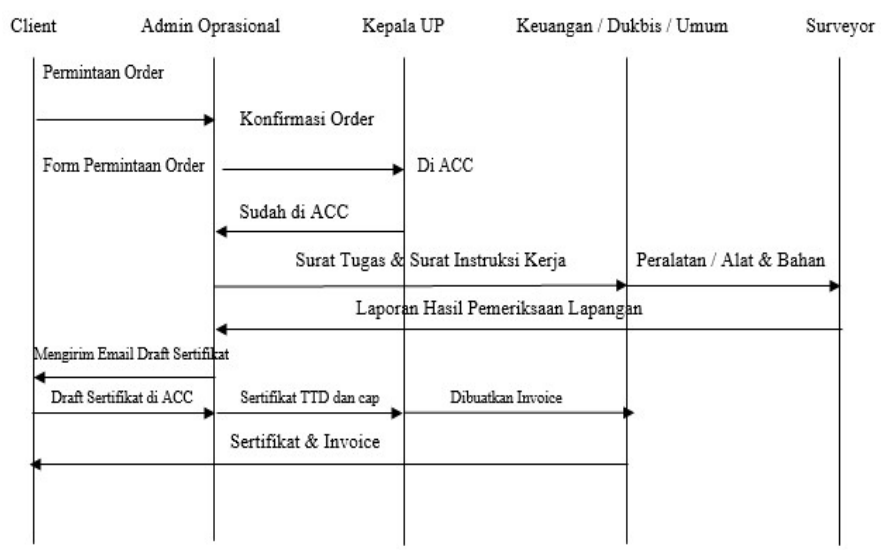

Gambar 3. Proses Bisnis (sesudah)

\section{B. Pemodelan Data}

Pemodelan data dalam rekayasa perangkat lunak adalah proses menciptakan sebuah model data dengan menerapkan model deskripsi formal data menggunakan teknik pemodelan data. Pemodelan data adalah metode yang digunakan untuk menentukan dan menganalisis persyaratan data yang diperlukan untuk mendukung proses bisnis. Data yang dibutuhkan adalah dicatat sebagai data model konseptual dengan definisi data yang terkait.

Pemodelan data merupakan sebuah tahapan dalam merancang sebuah sistem. Pemodelan data berfokus pada data apa yang akan disimpan yang menggambarkan hubungan antara entity set yang dibutuhkan dalam pengolahan data.

Tujuan dari tahap ini yaitu melakukan perancangan sistem berdasarkan analisis yang telah dilakukan sebelumnya. Tahap analisis dan desain mengalami pengulangan hingga diperoleh rancangan sistem yang benar-benar memenuhi kebutuhan.

Gambar 5 sequence diagram login, admin operasional mengakses form login, kemudian sistem memproses dan mengecek username dan password lalu mengecek id lebih detail, terus kirim pesan username dan password benar dan sistem menampilkan halaman login.

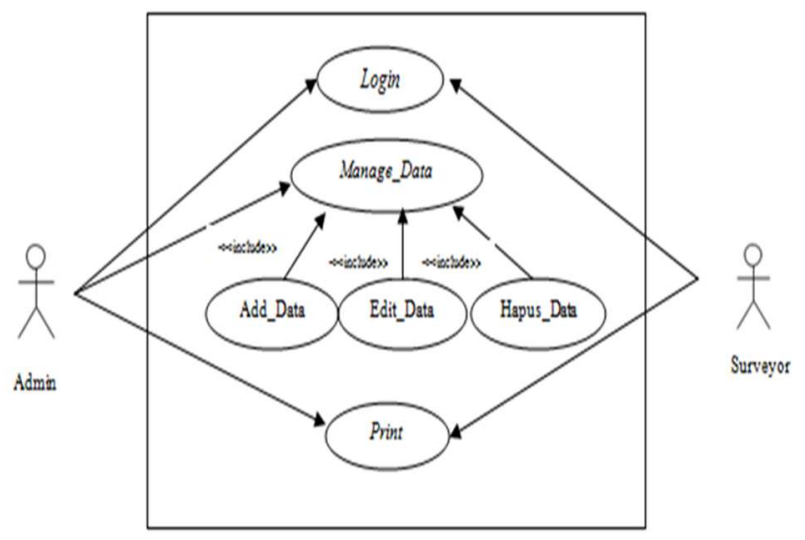

Gambar 4. Use Case Diagram Sistem Penerbitan Sertifikat

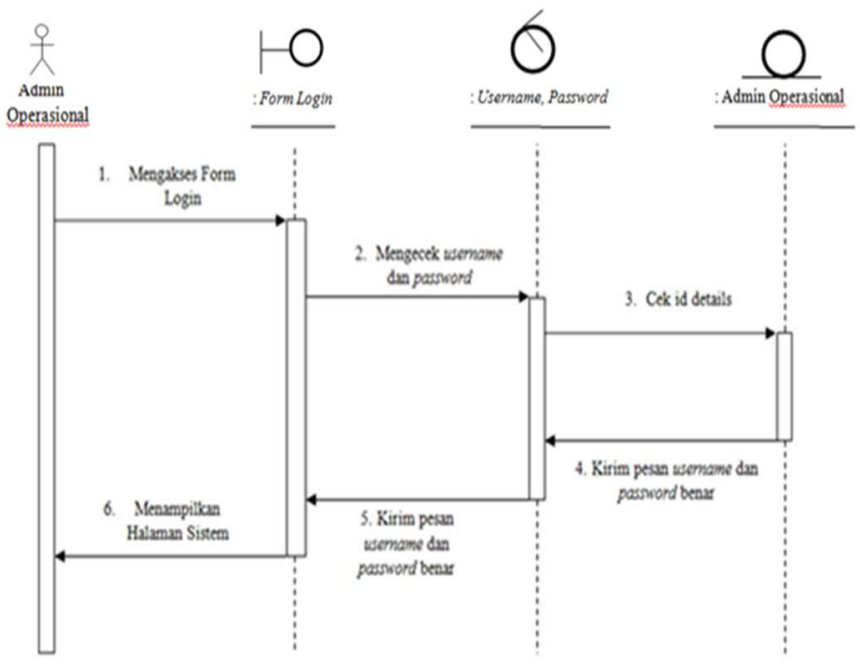

Gambar 5. Sequence Diagram Login 
TABEL I. DAFTAR INTERFACE, CONTROL, DAN ENTITY UNTUK SETIAP OBYEK

\begin{tabular}{|c|c|c|c|}
\hline Obyek & Interface & Control & Entity \\
\hline Login & $\begin{array}{l}\text { Form } \\
\text { login } \\
\text { admin } \\
\text { Form } \\
\text { login } \\
\text { surveyor }\end{array}$ & $\begin{array}{l}\text { Username, } \\
\text { Password }\end{array}$ & Surveyor \\
\hline $\begin{array}{l}\text { Tambah } \\
\text { Data }\end{array}$ & $\begin{array}{l}\text { Form } \\
\text { Tambah } \\
\text { Data }\end{array}$ & $\begin{array}{lr}\text { Jenis pekerjaan, } \\
\text { Nama pelanggan, } \\
\text { Tarif / Biaya, } \\
\text { Kuantitas, Satuan, } \\
\text { Tanggal mulai } \\
\text { pekerjaan, Tanggal } \\
\text { selesai pekerjaan, } \\
\text { Lokasi, Nama } \\
\text { Surveyor, Rencana } \\
\text { Berangkat, } \\
\text { Rencana Selesai, } \\
\text { Nomor Order, } \\
\text { Nama Sertifikat, } \\
\text { Tambah Dokumen. }\end{array}$ & Admin, \\
\hline Edit Data & $\begin{array}{l}\text { Form } \\
\text { Edit Data }\end{array}$ & $\begin{array}{lr}\text { Jenis pekerjaan, } \\
\text { Nama pelanggan, } \\
\text { Tarif / Biaya, } \\
\text { Kuantitas, Satuan, } \\
\text { Tanggal mulai } \\
\text { pekerjaan, Tanggal } \\
\text { selesai pekerjaan, } \\
\text { Lokasi, Nama } \\
\text { Surveyor, Rencana } \\
\text { Berangkat, } \\
\text { Rencana Selesai, } \\
\text { Nomor Order, } \\
\text { Nama Sertifikat, } \\
\text { Tambah Dokumen. }\end{array}$ & Admin, \\
\hline $\begin{array}{l}\text { Hapus } \\
\text { Data }\end{array}$ & $\begin{array}{l}\text { Form } \\
\text { Hapus } \\
\text { Data }\end{array}$ & 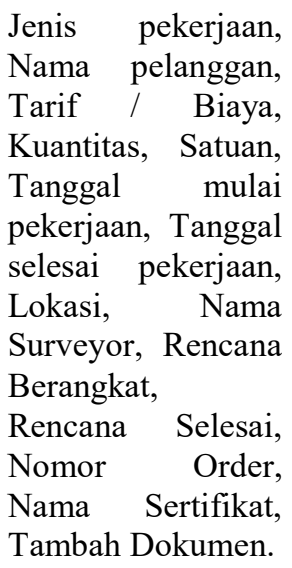 & Admin \\
\hline $\begin{array}{l}\text { Registrasi } \\
\text { Surveyor }\end{array}$ & $\begin{array}{l}\text { Form } \\
\text { Registrasi } \\
\text { Surveyor }\end{array}$ & $\begin{array}{l}\text { Username, } \\
\text { password }\end{array}$ & Admin, \\
\hline
\end{tabular}

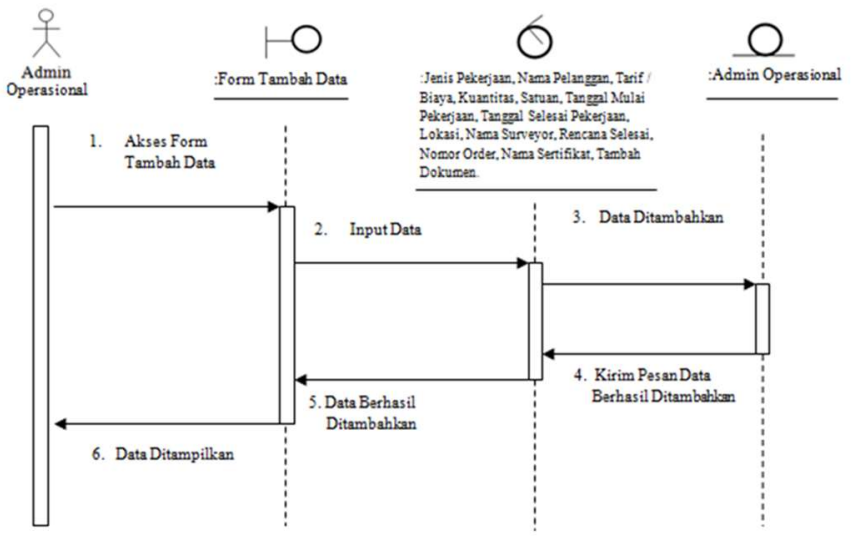

Gambar 6. Sequence Diagram Tambah Data

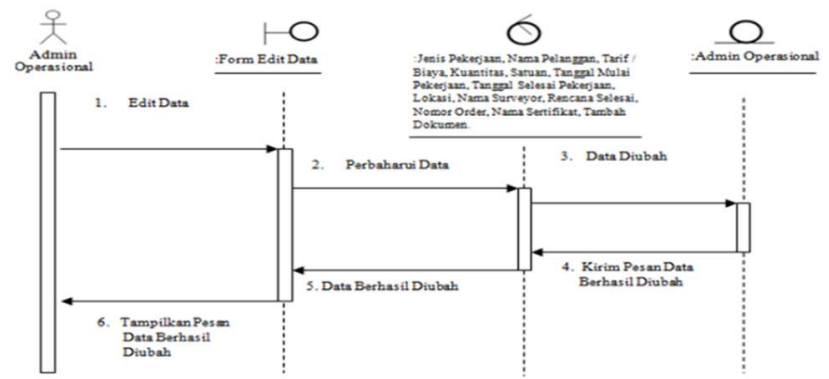

Gambar 7. Sequence Diagram Edit Data

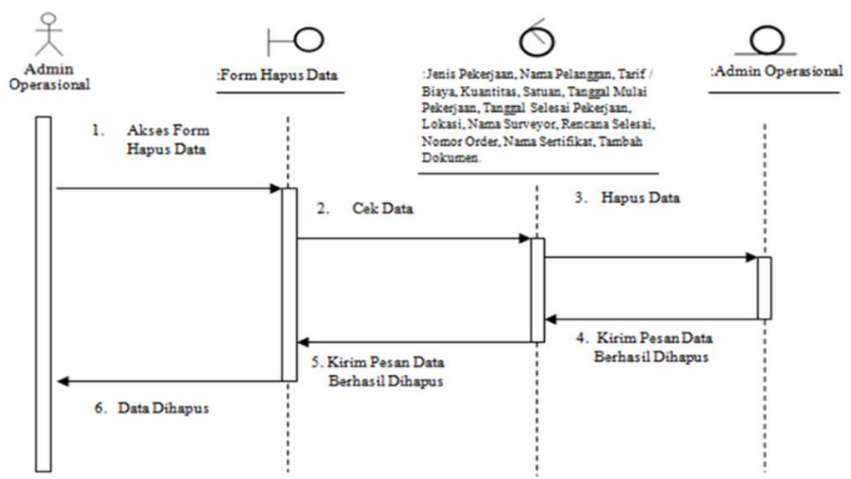

Gambar 8. Sequence Diagram Hapus Data

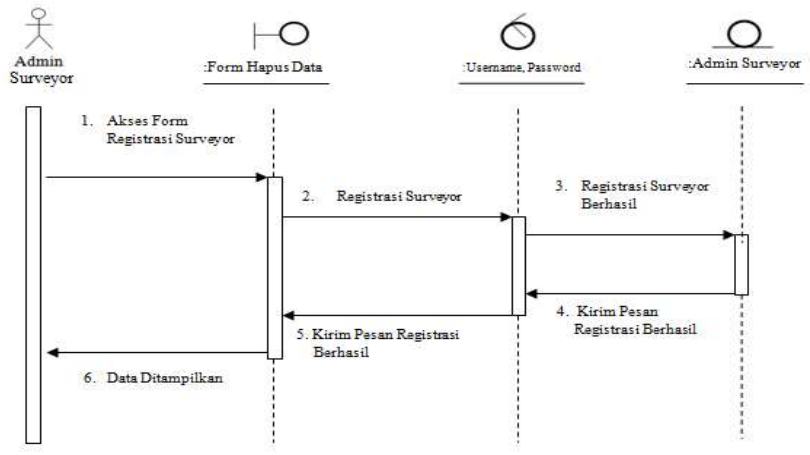

Gambar 9. Sequence Diagram Registrasi Surveyor 
Gambar 6. sequence diagram tambah data, admin mengakses form tambah data, lalu menginput data dari mulai jenis pekerjaan sampai dengan tambah dokumen kemudian data ditambahkan lalu kirim pesan data berhasil ditambahkan dan data berhasil ditambahkan kemudian data ditampilkan.

Gambar 7. Sequence diagram edit data, admin operasional mengedit data yang ingin diperbarui kemudian data diubah dan mengirim pesan data berhasil diubah dan sistem menampilkan data yang berhasil diubah.

Gambar 8. Sequence diagram hapus data, admin operasional mengakses form hapus data lalu sistem mengecek data apa yang akan dihapus kemudian data dihapus dan mengirim pesan data berhasil dihapus.

Gambar 9. Sequence diagram registrasi surveyor, surveyor mengakses for registrasi kemudian surveyor meregis data dan hasil registrasi surveyor berhasil lalu mengirimpesan registrasi berhasil dan data ditamplikan.

\section{Perancangan Antar Muka}

Gambar 10. Merupakan halaman login. Jika belum punya akun, silahkan klik Daftar disini untuk buat akun. Akun yang akan didaftarkan ada 2 jenis akun. Yang pertama sebagai Admin dan yang kedua sebagai Surveyor.

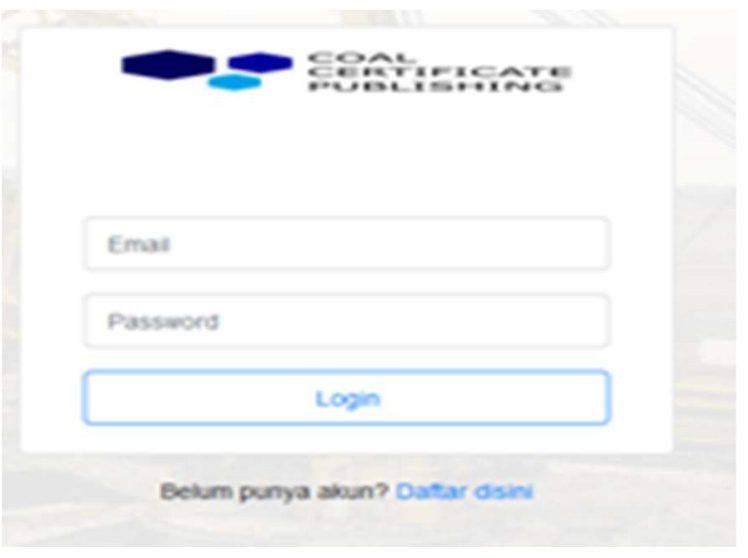

Gambar 10. Halaman Login

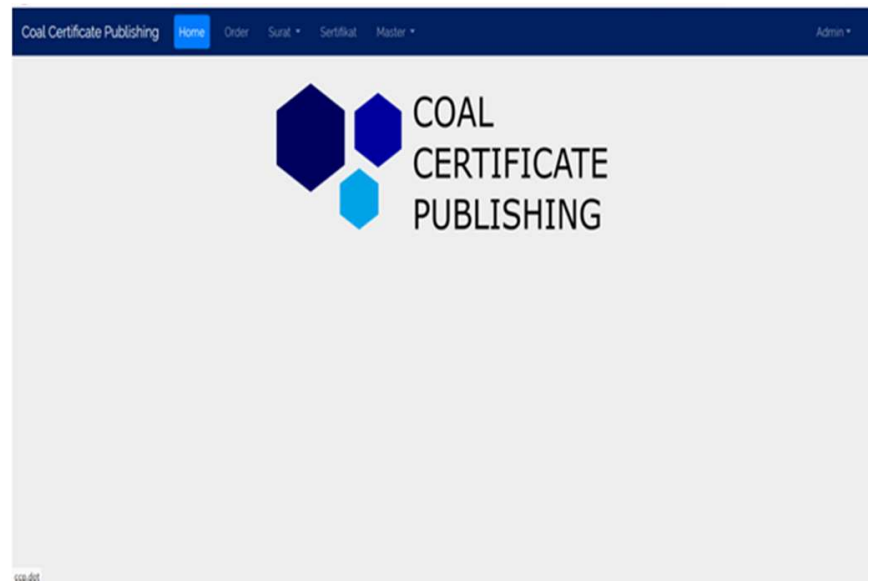

Gambar 11. Halaman Home Admin
Gambar 11. Merupakan tampilan Home yang login sebagai admin. Setelah login sebagai admin, admin akan mengaktifkan akun yang baru mendaftar sebagai Surveyor. Jika nama akun tidak dikenal maka admin tidak akan mengaktifkan akun tersebut.

Gambar 12. Halaman Home di login dengan akun Surveyor yang sudah diaktifkan oleh admin. Akun surveyor hanya bisa melihat dan mencetak Surat Tugas dan Surat Instruksi Kerja yang dibuat oleh admin.

Gambar 13. Adalah tampilan menu order untuk menambah data order baru yang masuk.

Gambar 14. Merupakan tampilan form pengisian order baru dengan memilih jenis pekerjaan, memasukkan jumlah kuantitas, memilih satuan, memaukkan nama pelanggan, tarif / biaya, rencana pekerjaan dan terakhir adalah lokasi pekerjaan.

Gambar 15. Adalah tampilan untuk menambah data surat tugas, klik tambah surat tugas pada bagian kanan atas.

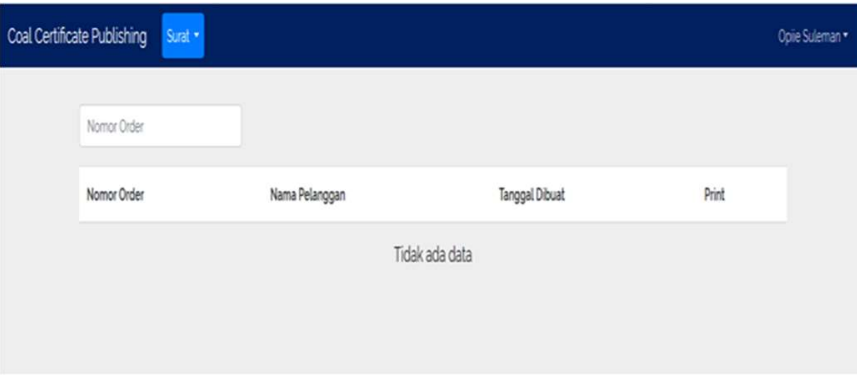

Gambar 12. Halaman Home Surveyor

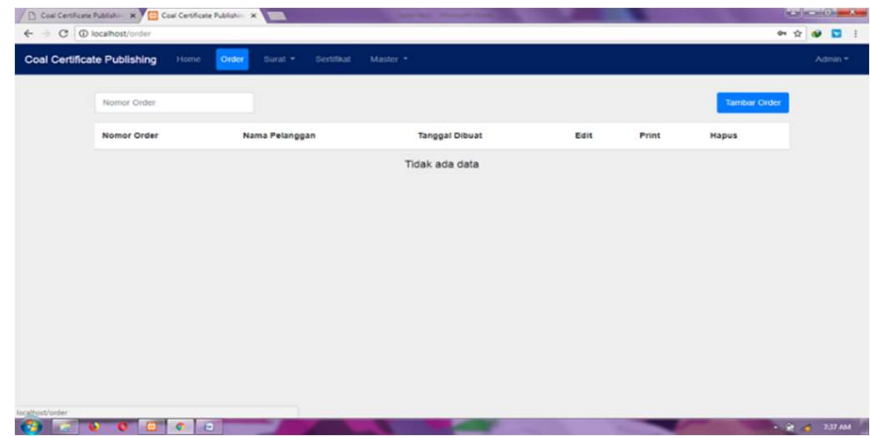

Gambar 13. Menu Order

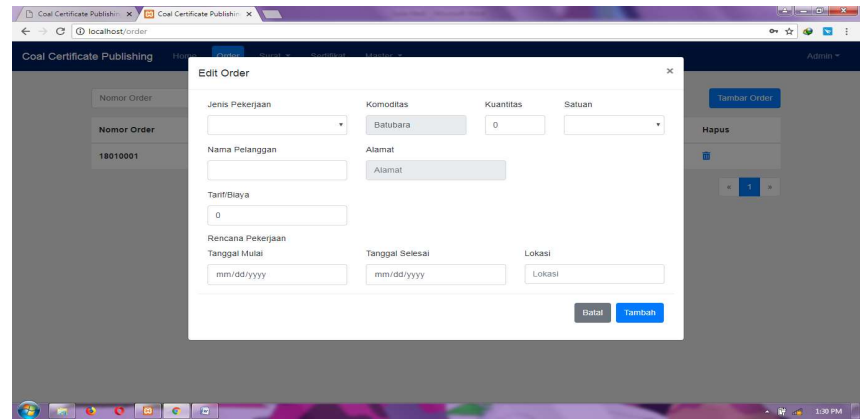

Gambar 14. Form Pengisian Order 
Gambar 16. Adalah form pengisian surat tugas dengan menginput nama surveyor, rencana pekerjaan dan nomor order.

Gambar 17. Adalah tampilan menu surat instruksi kerja untuk menambahkan surat instruksi kerja baru.

Gambar 18. Merupakan tampilan form tambah surat instruksi kerja, dengan hanya menginput nomor order yang akan dibuatkan surat instruksi kerja.

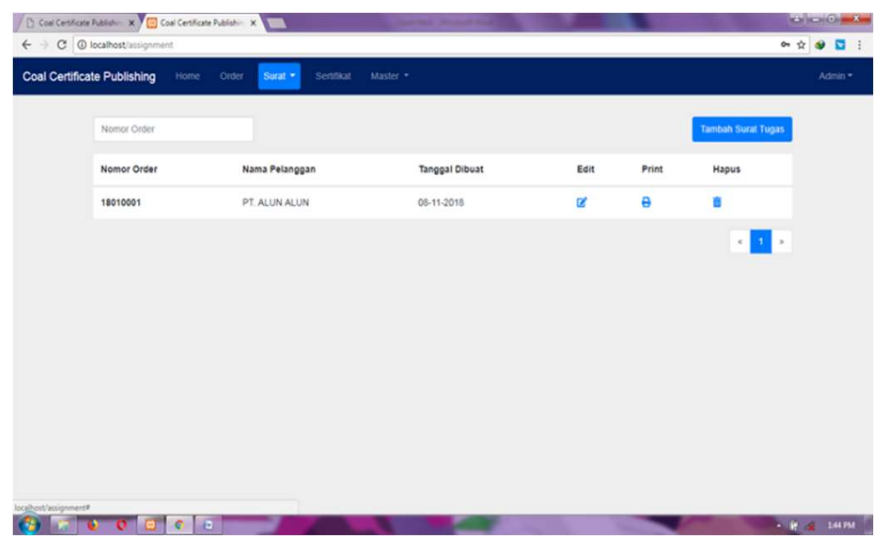

Gambar 15. Menu Tambah Surat Tugas

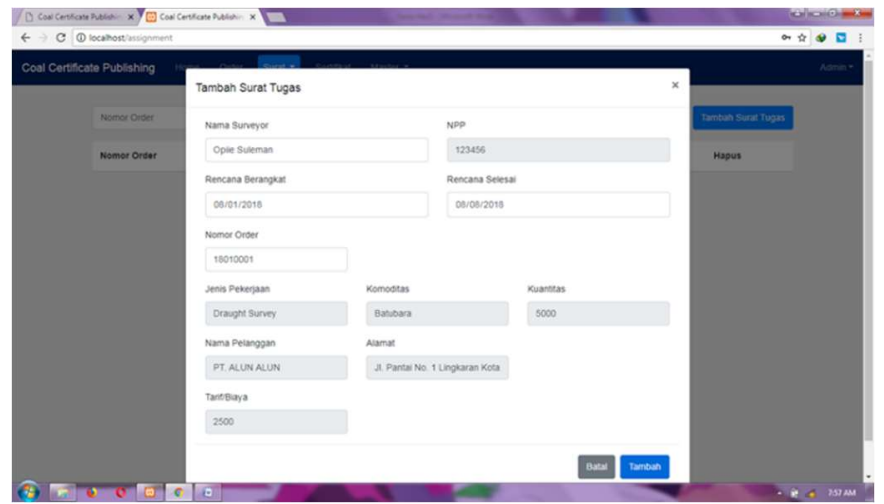

Gambar 16. Form Pengisian Surat Tugas

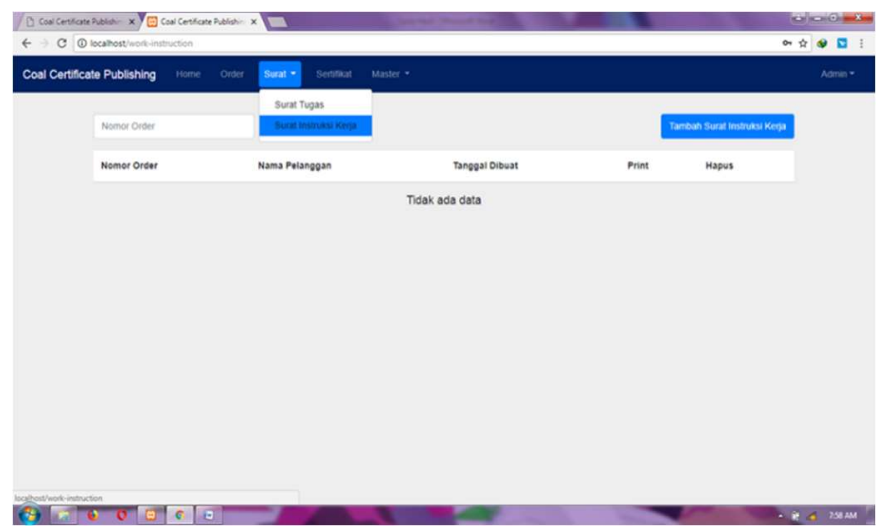

Gambar 17. Menu Surat Instruksi Kerja
Gambar 19. Adalah tampilan menu sertifikat untuk membuat sertifikat berdasarkan nomor order.

Gambar 20. Merupakan form tambah sertifikat untuk mengisi nama sertifikat apa yang akan dibuat dan memilih file dokumennya.

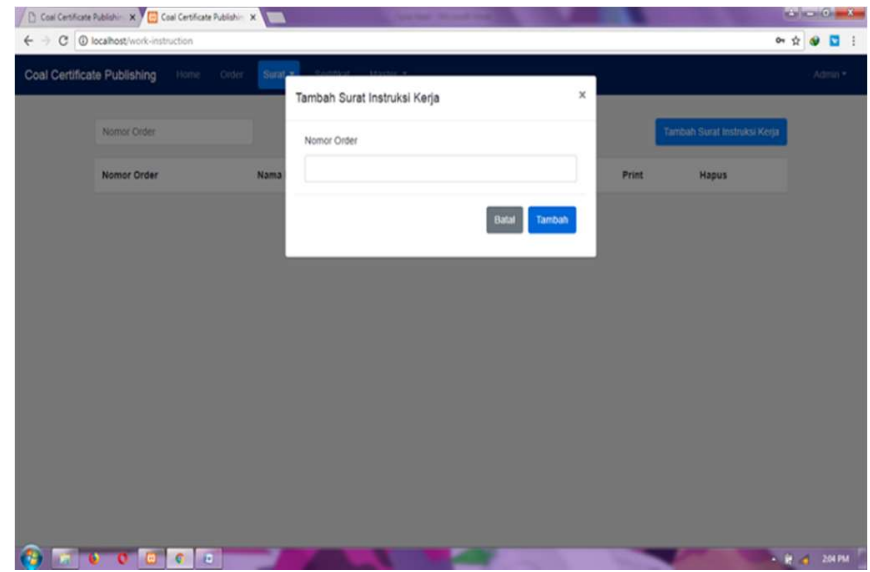

Gambar 18. Form Tambah Surat Instruksi Kerja

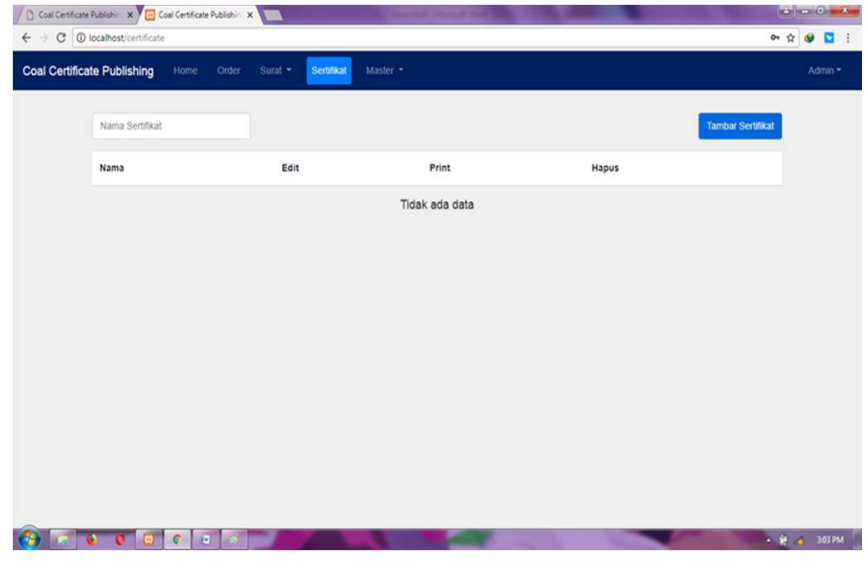

Gambar 18. Menu Sertifikat

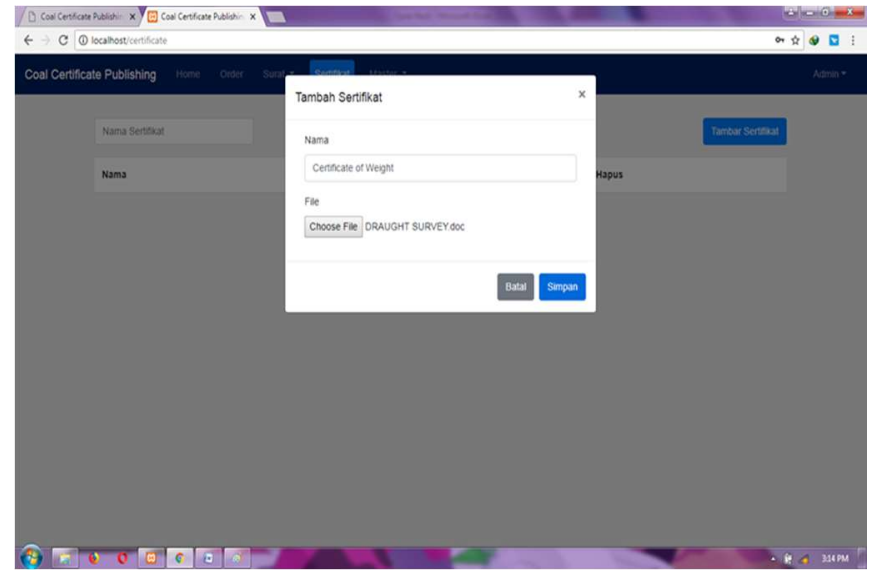

Gambar 18. Form Tamabah Sertifikat 


\section{PENUTUP}

\section{A. Kesimpulan}

Dari hasil penelitian, perancangan dan implementasi yang telah dilakukan ada beberapa kesimpulan yang dapat dikemukakan sebagai berikut:

1) Dengan adanya "Aplikasi Sistem Penerbitan Sertifikat PT. Sucofindo", Surveyor tidak perlu lagi jauh-jauh ke kantor untuk mencetak surat tugas dan surat instruksi kerja kepada admin operasional karena aplikasi ini bisa di akses oleh surveyor dimana saja dan dicetak langsung oleh surveyor.

2) Aplikasi Sistem Penerbitan Sertifikat PT. Sucofindo ini dirancang sebagai solusi untuk memanage waktu dalam pekerjaan di lapangan.

3) Hanya kalangan tertentu yang memiliki hak akses terhadap sistem ini yaitu administrator dan surveyor.

\section{B. Saran}

Pengembangan selanjutnya adalah menambah jumlah komoditi dan jenis pekerjaan. Misalnya komoditi makanan seperti sayur-sayuran dan buah-buahan untuk di analisa parameternya.

\section{KUTIPAN}

[1] Riani, Selvia. 2014. Prosedur Penerbitan Sertifikat Analisis (Certificate Of Analysis) dan Sertifikat Mutu (Certificate Of Quality) Komoditi Karet Ekspor pada PT. Hok Tong Keramasan. Program Studi Administrasi Bisnis. Jurusan Administrasi Bisnis. Politeknik Negeri Sriwijaya.

[2] Rochman, Abdul. Perancangan Sistem Informasi Keuangan Masjid Raudatul Jannah Makassar. Teknik Informatika. STMIK Handayani.

[3] Supriyono, Risma Prihartanti. 2012. Analisa dan Perancangan Sistem Informasi Sekolah di Kabupaten Kudus Berbasis Web. Fakultas Teknik UMK.

[4] Wuner, Stevi A. Analisa dan Perancangan Sistem Informasi Poliklinik Unsrat Berbasis Web. Program Studi Teknik Informatika. Fakultas Teknik. Universitas Sam Ratulangi Manado

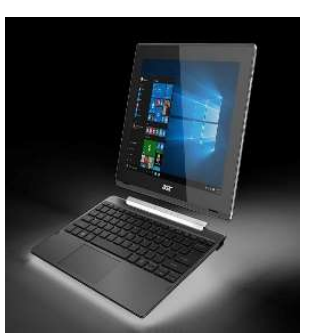

Penulis bernama Bahmid Hadi lahir di Desa Marekofo, Kecamatan Tidore Selatan, Kota Tidore Kepulauan pada tanggal 05 bulan April tahun 1992 dan merupakan anak ke lima dari pasangan Hadi Laha dan Rabiha Nuru.

Penulis mulai menempuh Pendidikan formal pertama di Sekolah Dasar SDN Marekofo tahun 1999 dan lulus pada tahun 2005. Kemudian, penulis menempuh Pendidikan pada Sekolah Menengah Pertama di SMP Muhamadiyah 1 Kota Tidore Kepulauan tahun 2005 dan lulus 2008. Selanjutnya, penulis melanjutkan menempuh Pendidikan ke Sekolah Menengah Kejuruan SMK Negeri 1 Kota Tidore Kepulauan, Provinsi Maluku Utara tahun 2008 dan lulus pada tahun 2011. Pada tahun 2011, setelah lulus dari SMK Negeri 1 Kota Tidore Kepulauan, penulis melanjutkan Pendidikan ke jenjang Perguruan Tinggi di Universitas Sam Ratulangi Manado, Fakultas Teknik, Jurusan Teknik Elektro, Program Studi Teknik Informatika. Selama masa kuliah penulis menjalani aktivitas luar Kampus dengan mengikuti Organisasi Ekstra di Pergerakan Mahasiswa Islam Indonesia (PMII) Cabang Manado dan Organisasi Paguyuban yang di kenal dengan nama Forum Mahasiswa Kota Tidore Kepulauan (FOMAKATI) Manado.

Pada bulan Agustus 2018, Alhamdulillah penulis dinyatakan lulus melalui Sidang Sarjana Program Studi Teknik Informatika, Universitas Sam Ratulangi dengan menyandang Gelar Sarjana Komputer (S.Kom). 